obtained by summing the squared projections of all the haem planes on to the form ellipsoid of the molecule, and this was then transformed into the crystallographic system.

After defining the limits of the orientation of the $x$ axis, and using the Finch stacked-ring model for the molecular positions, with the requirement that at least one mutation $(\beta 6)$ site is part of an intermolecular contact, the measured polarisation ratio for the Soret band requires that the true molecular dyad $(y)$

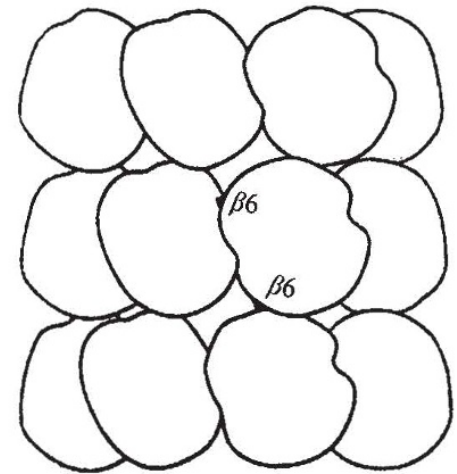

Diagram of one of the three classes of model for the orientation of mo'scules in the sickle cell fibre allowed by the optical results of Hofrichter et al. and by the additional constraint that at least one $\beta 6$ site is part of an intermolecular contact. If the maximum possible tilt of the $x$ axis is used, the other $\beta 6$ residue of a molecule is in a position to make an interring contact.

axis passes through some part of an adjacent molecule in the same ring of six molecules. This range of orientation for the $y$ axis turns out to be approximately perpendicular to those proposed in previous models.

The new information obtained from the optical studies allows three classes of model to be considered, which differ in respect of the possible dispositions of the $\beta 6$ sites. In all three models a $\beta 6$ residue could assist in stabilising intraring contacts. If the maximum possible tilt of the $x$ axis is used, the other $\beta 6$ residue of a molecule is in a position to make an interring contact, though more extensive polarised absorption measurements will be required to establish this interesting possibility. In any case the absorption polarisation work, which is technically very impressive, has already provided new insights into the detailed structure of the deoxy Hb-S fibre and may suggest new approaches to the practical problem of inhibiting the aggregation process.

\section{Not all at sea on the Channel}

ON Thursday, January 31 , a large contingent of French scientists converged upon London to meet their English counterparts for two days of discussion on the geology of the English Channel. Although physical constraints required that the scientists meet in either London or Paris, metaphorically they met half way-a great deal of academic entente was evident throughout the proceedings. The meeting, jointly organised by the Royal Society and the Marine Studies Group of the Geological Society, was a great success. And it was not without its surprises: "I began", said one of the organisers, "by asking for volcanoes, and in the end I was given ice".

But despite the more surprising aspects, the meeting showed that a new understanding of Channel geology has emerged which will not only have important implications in future studies of the geology of north-western Europe, but which may well result in a considerable reappraisal of established theories concerning that area. This is largely due to the amount of detail about the basement geology which has been collected by the French scientists.

There is evidence to indicate that the region has had an important tectonic history, the effects of which have not been fully appreciated in the past. There have been two major phases in the history of the Channel, probably interspersed with many minor tectonic events. A. J. Smith (University College, London) believes that both phases are intimately associated with events in the history of the spreading Atlantic Ocean. Soon after the end of the Hercynian orogeny about 280 million years ago, the Atlantic began to open along a trend aligned with that of the Channel, and many of the primary structures of the Channel originated at this time. During the Early Cretaceous, probably about 130 m.y. ago, the second phase developed as the Bay of Biscay opened and the axial trend of the Atlantic changed to its present orientation.

Consideration of the present structure and geology of the Channel shows that its tectonic history must have had some influence on the geological evolution of northern France and southern Britain. The Channel can be divided into three areas on a structural basis: an area to the west of the Anglo-Norman Ridge; a central area between this ridge and the Bembridge-St Valery Line; and a third area to the east. It is as a result of studies of the central area that geologists have come to appreciate the importance of the Channel's tectonic history. Within this central region two east-west structures downturn beds to the south. Geophysical data indicate that the tectonic activity in the Channel has been largely restricted to vertical block movements of the basement (which to some extent are still continu- ing), and the surface structures of the central area are probably reflections of the basement structure. But, the important fact is that the southernmost of these two structures joins the Bembridge-St Valery Line and becomes deflected onto the French coast. The deflected structure has become a very minor feature by the time it reaches the coast, but, significantly, it is in perfect alignment with major structural features which pass through northern France, and into the Massif Central. Furthermore, the northern extension of the Bembridge-St Valery Line passes into important structures in south Dorset.

The implication is that major structural features which have previously been interpreted without any consideration of the role of the events which are manifest in the Channel, will now have to be examined more closely. Are the Mendips really just part of the Hercynian Front, or do they in fact reflect the vertical movements of the basement rocks of this area? And was the Weald really folded into its present structure by epeirogenic movements during the Alpine orogeny; or is D. Curry (University College, London) correct in the reiteration of his old idea that the Hampshire, London and Somme basins did not form separately?

But despite the implications raised by these issues it was largely the wellreceived theory of G. A. Kellaway (Institute of Geological Sciences, London) and his colleagues which dominated the discussions. Early on in the meeting Smith had suggested that there may have been considerable volcanicity accompanying the first major tectonic phase, and that the lavas which accumulated may be responsible for the present isostatic balance which leaves the western area of the Channel as a basinal depression. Unfortunately none of the other speakers could provide proof for this attractive hypothesis, and so Kellaway, unable to provide a volcano, provided a glacier instead. He has managed to find an impressive amount of evidence, including boulder clay from the Slinden Pipes, to show that during the Anglian glacial advance the Channel was filled with glacial ice which moved eastwards from the edge of the continental shelf, and deposited the abundant erratics which today litter the coastline of southern England.

Kellaway also believes that the 'raised beaches' around the Sussex coastline are not raised beaches at all, but are marginal outwashed deposits. His theory could certainly provide an acceptable explanation for the previously mysterious buried channels and valleys and for the Hurd Deep, all of which may be the result of subglacial erosion. 